\title{
Impacto das mudanças climáticas no zoneamento agroclimático do café no Brasil
}

\author{
Eduardo Delgado Assad ${ }^{(1)}$, Hilton Silveira Pinto(2), Jurandir Zullo Junior ${ }^{(2)}$ e Ana Maria Helminsk Ávila(2) \\ (1)Embrapa Informática Agropecuária, Caixa Postal 6041, CEP 13086-970 Campinas, SP. E-mail: assad@cnptia.embrapa.br (2)Universidade \\ Estadual de Campinas, Centro de Pesquisas Meteorológicas e Climáticas Aplicadas à Agricultura, Cidade Universitária "Zeferino Vaz", \\ CEP 13083-970 Campinas, SP. E-mail: hilton@cpa.unicamp.br, jurandir@cpa.unicamp.br, ana@cpa.unicamp.br
}

Resumo - A partir das indicações do último relatório do IPCC (International Pannel of Climatic Change), foram feitas várias simulações e avaliados os impactos que um aumento na temperatura média do ar de $1^{\circ} \mathrm{C}, 3^{\circ} \mathrm{C}$ e $5,8^{\circ} \mathrm{C}$ e um incremento de $15 \%$ na precipitação pluvial teriam na potencialidade da cafeicultura brasileira, definida pelo atual zoneamento agroclimático do café (Coffea arábica L.) nos Estados de Goiás, Minas Gerais, São Paulo e Paraná. Os resultados indicaram uma redução de área apta para a cultura superior a 95\% em Goiás, Minas Gerais e São Paulo, e de 75\% no Paraná, no caso de um aumento na temperatura de 5,8 $\mathrm{C}$. Esses resultados são válidos se mantidas as atuais características genéticas e fisiológicas das cultivares de café arábica utilizadas no Brasil, que têm como limite de tolerância temperaturas médias anuais entre $18^{\circ} \mathrm{C}$ e $23^{\circ} \mathrm{C}$.

Termos para indexação: Coffea arabica, zoneamento agrícola, aumento de temperatura.

\section{Climatic changes impact in agroclimatic zonning of coffee in Brazil}

\begin{abstract}
According to the last report of the Intergovernmental Panel on Climate Change (IPCC), the global temperature is supposed to increase $1^{\circ} \mathrm{C}$ to $5.8^{\circ} \mathrm{C}$ and the rainfall $15 \%$ in the Tropical area. This paper analyses the effect that these possible scenarios would have in the agroclimatic zoning of the arabic coffee (Coffea arabica L.) main plantation areas in Brazil. The results indicated a reduction of suitable areas greater than $95 \%$ in Goiás, Minas Gerais and São Paulo and about $75 \%$ for Paraná in the case of a temperature increase of $5.8^{\circ} \mathrm{C}$. These results presume that all the physiological characteristics of the crop will be the same for the varieties analyzed and that the ideal climatic condition for economic development is mean annual temperatures between $18^{\circ} \mathrm{C}$ and $23^{\circ} \mathrm{C}$.
\end{abstract}

Index terms: climatic change, agroclimatic zoning, Coffea arabica.

\section{Introdução}

A problemática das mudanças climáticas globais levou a Organização Meteorológica Mundial (OMM) e a UNEP (United Nations Environment Programme) a criarem o IPCC (Intergovernmental Panel on Climate Change) em 1988. Segundo o IPCC, no século XX, houve um aumento de $0,65^{\circ} \mathrm{C}$ na média da temperatura global, sendo este mais pronunciado na década de 90 . Quanto à precipitação, o aumento variou de $0,2 \%$ a $0,3 \%$ na região tropical, compreendida entre $10^{\circ}$ de latitude Norte e $10^{\circ}$ de latitude Sul. As causas dessas variações podem ser de ordem natural ou antropogênica, ou uma soma das duas (IPCC, 2004).

Por meio de modelos matemáticos baseados em dados registrados dos oceanos, biosfera e atmosfera, está previsto um aumento entre $1,4^{\circ} \mathrm{C}$ e $5,8^{\circ} \mathrm{C}$ na temperatu- ra média global até o final do século XXI (IPCC, 2004). A magnitudes de tal previsão é ainda incerta, pois pouco se sabe sobre os processos de trocas de calor, de carbono e de radiação entre os diversos setores do sistema Terra. Segundo Kalnay \& Cai (2003), a temperatura poderá subir em até $0,088^{\circ} \mathrm{C}$ por década, chegando próximo da situação mais otimista indicada no relatório do IPCC.

Com o aquecimento global, em um futuro próximo, espera-se cenário de clima mais extremo com secas, inundações e ondas de calor mais freqüentes (Salati et al., 2004). A elevação na temperatura aumenta a capacidade do ar em reter vapor d'água e, conseqüentemente, há maior demanda hídrica. Em resposta a essas alterações, os ecossistemas de plantas poderão aumentar sua biodiversidade ou sofrer influências negativas.

Pesq. agropec. bras., Brasília, v.39, n.11, p.1057-1064, nov. 2004 
Segundo Thomas et al. (2004), com a elevação das temperaturas, 18 espécies estarão ameaçadas de extinção até o ano de 2050, considerando o cenário mais otimista. Impactos como a elevação do nível dos oceanos e furacões mais intensos e mais freqüentes também poderão ser sentidos, assim como o derretimento das geleiras (Salati et al., 2004).

O Brasil, com sua dimensão continental, possui uma considerável heterogeneidade climática, tipos de solo e topografia. Considerando-se os prognósticos de aumento das temperaturas, pode-se admitir que as regiões climaticamente limítrofes àquelas de delimitação de cultivo adequado de plantas agrícolas se tornarão desfavoráveis ao desenvolvimento vegetal. Quanto maior a anomalia, menor a aptidão da região, até o limite máximo de tolerância biológica ao calor. Culturas tolerantes a altas temperaturas provavelmente serão beneficiadas até o seu limite próprio de tolerância ao estresse térmico. No caso de baixas temperaturas, regiões que atualmente são limitantes ao desenvolvimento de culturas suscetíveis a geadas, com o aumento do nível térmico decorrente do aquecimento global, passarão a apresentar condições favoráveis ao desenvolvimento de vegetações.

Nas plantas, o aumento da temperatura é diretamente proporcional à atividade fotossintética. As reações catalisadas enzimaticamente podem ser aceleradas, resultando na perda da atividade das enzimas, fator este associado à tolerância das plantas ao calor (Bieto \& Talon, 1996). No caso do cafeeiro da espécie Coffea arabica, temperaturas médias anuais ótimas situam-se entre $18^{\circ} \mathrm{C}$ e $22^{\circ} \mathrm{C}$. A ocorrência freqüente de temperaturas máximas superiores a $34^{\circ} \mathrm{C}$ causa o abortamento de flores e, conseqüentemente, perda de produtividade (Camargo, 1985; Pinto et al., 2001; Sediyama et al., 2001). Temperaturas entre $28^{\circ} \mathrm{C}$ e $33^{\circ} \mathrm{C}$ provocam um redução na produção de folhas e na atividade fotossintética do cafeeiro ( Drinnan \& Menzel, 1995).

Segundo Marengo (2001) o número de frentes frias relacionadas às geadas intensas no Sul do Brasil diminuiu com o decorrer do tempo, havendo uma tendência de invernos mais quentes. Apesar disso, entre os anos de 1882 e 2000, foram identificadas 42 geadas prejudiciais ao cafeeiro, na região Sul e Sudeste, com 35\% dos eventos provocando perdas na produção. Conforme Caramori et al. (2001), Pinto et al. (2001) e Sediyama et al. (2001), para efeito do zonenamento do café, a tem- peratura mínima tolerável sem causar danos às folhas é de $0^{\circ} \mathrm{C}$ a $1^{\circ} \mathrm{C}$. No caso do zoneamento de riscos climáticos para o café no Brasil, apenas são consideradas em condição de financiamento da lavoura as regiões que apresentam risco de geada igual ou inferior a $25 \%$, ou seja, 75\% de chances de que a temperatura mínima seja igual ou superior a $1^{\circ} \mathrm{C}$. Para efeito de abortamento de flores, o mesmo zoneamento considera como tolerável a temperatura média mensal até $24^{\circ} \mathrm{C}$.

O objetivo deste trabalho foi verificar o efeito do incremento de temperatura no zoneamento de riscos climáticos da cafeicultura nos próximos 100 anos, nos estados de Goiás, Minas Gerais, São Paulo e Paraná.

\section{Material e Métodos}

O procedimento cartográfico para espacialização da temperatura foi baseado nos dados altimétricos fornecidos pelos Estados Unidos (2001) no arquivos GTOPO30, no formato de uma grade regular com espaçamento de 30 segundos por 30 segundos de grau nas coordenadas geográficas. A temperatura média anual e a probabilidade de geadas foram calculadas para cada ponto da grade, utilizando equações de regressão, considerando a latitude, longitude e altitude de cada ponto, relativos aos estados de São Paulo e Paraná (Pinto et al., 1972), Minas Gerais (Seidyama et al., 2001) e Goiás (Assad et al., 2001a). As equações para estimar a temperatura em cada Estado encontram-se na Tabela 1. O cálculo da deficiência hídrica anual foi feito a partir da estimativa do balanço hídrico climático utilizando o método de Thornthwaite \& Mather (1955), considerando um armazenamento de água no solo correspondente a $125 \mathrm{~mm}$.

Os valores de deficiência hídrica anual foram espacializados com base na mesma grade regular utilizada no cálculo da probabilidade de geadas e temperatura média anual. Os riscos climáticos para a cafeicultura nos Estados foram definidos a partir dos valores de deficiência hídrica anual, temperatura média anual e probabilidade de geadas para cada ponto da grade regular. Esse procedimento gerou o zoneamento de riscos climáticos utilizado atualmente. Para efeito de simulação, foram confeccionados novos mapas de temperaturas com valores incrementados de $1^{\circ} \mathrm{C}, 3^{\circ} \mathrm{C}$ e $5,8^{\circ} \mathrm{C}$, e um incremento linear de $15 \%$ no valor da precipitação pluvial diária das séries históricas utilizadas, procurando

Tabela 1. Equações para estimar a temperatura média anual, em função da altitude e latitudes locais, na grade regular de 30"x 30".

\begin{tabular}{lll}
\hline Estado & \multicolumn{1}{c}{ Equação } \\
\hline Goiás & $\mathrm{T}=29,035-0,005$ alt $-0,139 l a t$ & Autor \\
Minas Gerais & $\mathrm{T}=26,62-0,005511$ alt $-0,4695 l a t+0,1695 l o n g$ & Sediyama et al. (2001) \\
São Paulo & $\mathrm{T}=38,98-0,005783 a l t+0,011250 l a t$ & Pinto et al. (1972) \\
Paraná & $\mathrm{T}=45,6-0,047$ alt $-0,0159 l a t$ & Pinto et al. (1974) \\
\hline
\end{tabular}


acompanhar os cenários futuros de acordo com o IPCC (2001). Com esses novos valores de temperatura, as evapotranspirações foram recalculadas, assim como os novos valores do balanço hídrico do solo. Os resultados foram espacializados e as novas áreas com aptidão e risco climático foram definidas segundo os seguintes critérios: risco de geada (temperatura inferior a $1^{\circ} \mathrm{C}$ ), inferior a 25\% de probabilidade; temperatura média anual entre $18^{\circ} \mathrm{C}$ e $22^{\circ} \mathrm{C}$; temperatura média anual de até $23^{\circ} \mathrm{C}$ para cafeicultura irrigada e deficiência hídrica anual inferior a $150 \mathrm{~mm} / \mathrm{ano}$.

Para que fosse possível comparar espacialmente a variação do risco de geada, utilizou-se a equação desenvolvida por Pinto et al. (2001), uma vez que nesse caso foi considerado como geada a ocorrência de temperatura mínima menor ou igual a $1^{\circ} \mathrm{C}$, obtida em abrigo meteorológico.

A equação de probabilidade de ocorrência de geada definida por Camargo et al. (1993) é a seguinte: $\mathrm{P}_{\left(\mathrm{Tmin}<1^{\circ} \mathrm{C}\right)}=-2296,113+0,06446$ altitude $(\mathrm{m})+$ 0,14738.latitude(min) + 0,02887.longitude(min).

No estabelecimento do balanço hídrico após o recálculo da evaportranspiração, foram utilizados os dados de precipitação disponíveis quanto a cada estado (Assad et al., 2001b). Ao todo, em relação aos estados, foram utilizadas informações de 883 postos pluviométricos com mínimo de 15 anos de dados diários.

O mapa final foi elaborado a partir do cruzamento dos resultados obtidos seguindo os critérios definidos anteriormente: temperatura média entre $18^{\circ} \mathrm{C}$ e $22^{\circ} \mathrm{C}$, para café irrigado, temperatura média até $23^{\circ} \mathrm{C}$, deficiência hídrica menor que 150 mm e probabilidade de geada menor que $25 \%$. Normalmente, nos sistemas de informações geográficas, o cruzamento é feito plano a plano, utilizando critérios booleanos. Neste trabalho, realizou-se uma varredura para cada célula de 30"x30" de coordenadas geográficas. Em cada célula procedeuse ao teste de atendimento dos critérios para determinar se um ponto no espaço atendia às condições de aptidão definidas. Identificado o valor, foi estimada a área com aptidão climática para cultivo do cafeeiro.

\section{Resultados e Discussão}

O aumento da temperatura média anual do ar de $1^{\circ} \mathrm{C}$, $3^{\circ} \mathrm{C}$ e $5,8^{\circ} \mathrm{C}$ promoveu grande alteração nas regiões consideradas aptas para o cultivo do cafeeiro. No zoneamento atual do café no Estado de Goiás, existem dois níveis de condições climáticas: favorável com irrigação e desfavorável (Figura 1). Ao acrescentar $1^{\circ} \mathrm{C}$ na temperatura, ocorre um aumento na demanda evapotranspirativa, provocando maior deficiência hídrica,

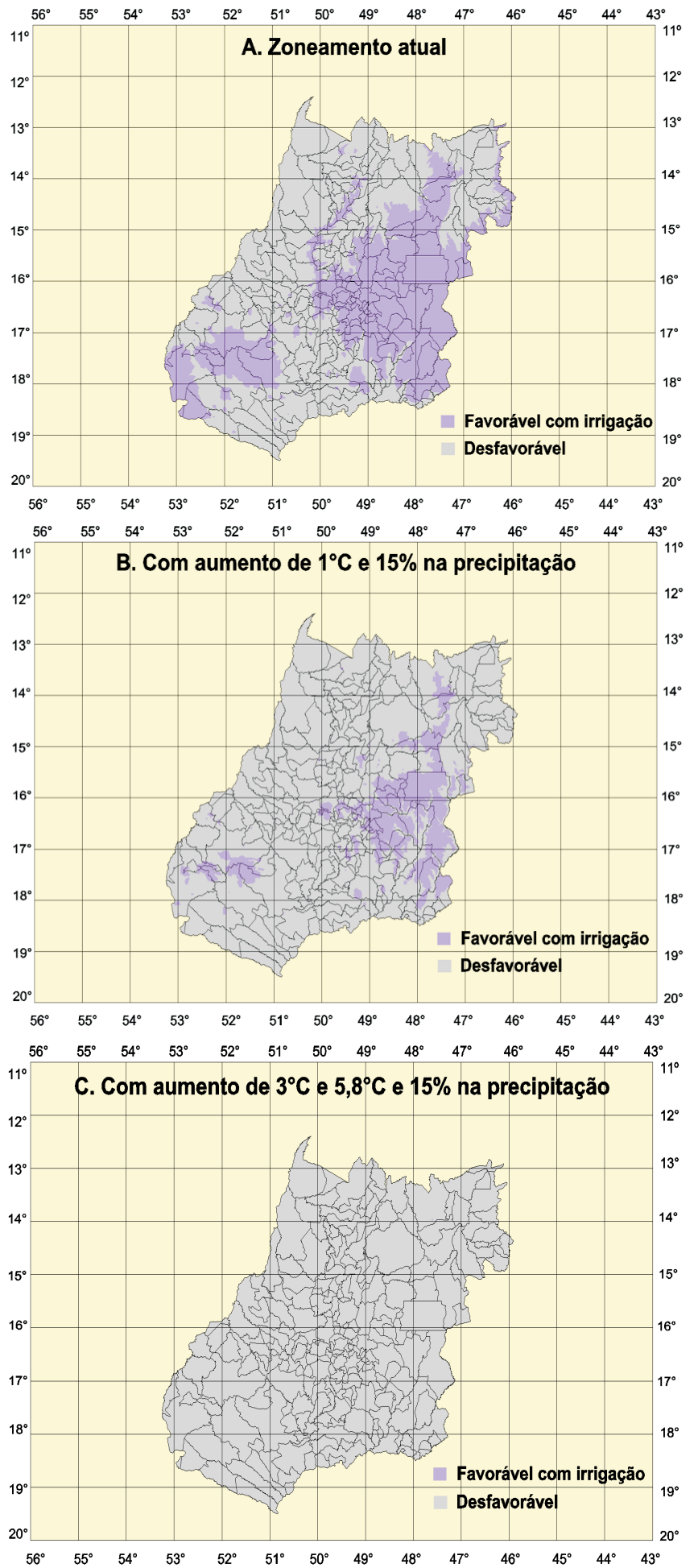

Figura 1. Zoneamento atual do café para o Estado de Goiás (A); Zoneamento considerando aumento de $1^{\circ} \mathrm{C}$ na temperatura e 15\% na precipitação pluvial (B); Zoneamento considerando aumento de $3^{\circ} \mathrm{C}$ na temperatura e $15 \%$ na precipitação pluvial (C). 
mesmo considerando um acréscimo de 15\% na precipitação pluvial. $\mathrm{O}$ acréscimo de $1^{\circ} \mathrm{C}$ na temperatura provoca um aumento de $61,6 \%$ para 85,9\% nas áreas inaptas para o cafeeiro da espécie Coffea arabica. Ao aumentar para $3^{\circ} \mathrm{C}, 99,9 \%$ do Estado de Goiás passa à condição de inapto, inclusive para o café irrigado (Figura 1). Na situação atual, a fim de garantir a produtividade neste Estado, recomenda-se o cultivo do café sob condição de irrigação. Em função das temperaturas elevadas, a irrigação aparece como regulador térmico, evitando o abortamento das flores. Com aumento da temperatura, e considerando somente o Cenário 1, aumento de temperatura de $1^{\circ} \mathrm{C}$, há uma diminuição de 38,6\% para $14,1 \%$ na área considerada apta com irrigação (Tabela 2). No Cenário 2, aumento de temperatura de $3^{\circ} \mathrm{C}$, a área apta com irrigação é praticamente eliminada. Mantida a tendência de aumento de temperatura nos próximos anos e considerando o cenário mais brando, a cafeicultura passa a ser uma prática de alto risco no Estado de Goiás, mesmo em condições de irrigação.

No Estado de Minas Gerais, foram identificadas cinco condições: região para cafeicultura com irrigação necessária; região com aptidão natural; região inapta por excesso térmico (temperatura média anual maior que $23^{\circ} \mathrm{C}$ ); região apta, mas com risco de geada; e região inapta. No primeiro cenário, isto é, aumento de $1^{\circ} \mathrm{C}$ na temperatura e $15 \%$ de acréscimo na precipitação pluvial, aparecem reduções na área com irrigação necessária no noroeste e centro do Estado e conseqüentemente deslocamento da área com potencial produtivo para o sul (Figura 2). O total da área inapta no Estado, que era de $24,1 \%$, passa para $43,3 \%$. Nesse primeiro cenário, foi observado um aumento na área naturalmente apta (baixo ou nenhum risco de geada ou excesso térmico), havendo um aumento de $8,9 \%$ para $12,4 \%$ da área total do Estado. Com o risco de geada reduzido, há um pequeno aumento, de 0,4\% para 1\%, de áreas restritas por excesso térmico.

No Cenário 2, aumento de $3^{\circ} \mathrm{C}$ na temperatura média anual, o cultivo do café fica mais restrito. Áreas com risco de geada praticamente desaparecem. A área com produção sob condição de irrigação atingiria somente 6,1\% do Estado; e 76,3\% da área total seria considerada inapta para a cultura do café.

No Cenário 3, mais pessimista, a cultura do café passa a ser possível apenas em 2,6\% da área do Estado, e concentrada em alguns municípios do sul, nas regiões montanhosas e de difícil manejo. Esses municípios seri-

Tabela 2. Resultados finais da simulação do zoneamento do café em função dos cenários de mudanças climáticas apresentados pelo IPCC.

\begin{tabular}{|c|c|c|c|c|c|c|}
\hline \multirow[t]{2}{*}{ Cenário } & \multicolumn{6}{|c|}{ Porcentagem da área do estado por classe de aptidão no zoneamento do café } \\
\hline & Inapto & $\begin{array}{l}\text { Excesso } \\
\text { térmico }\end{array}$ & $\begin{array}{l}\text { Risco de } \\
\text { geada }\end{array}$ & $\begin{array}{c}\text { Irrigação } \\
\text { recomendada }\end{array}$ & Apto & $\begin{array}{c}\text { Irrigação } \\
\text { necessária } \\
\end{array}$ \\
\hline & \multicolumn{6}{|c|}{ Minas Gerais } \\
\hline Atual & 24,1 & 0,4 & 9,7 & 19,1 & 8,9 & 37,7 \\
\hline$+1^{\circ} \mathrm{C}+15 \%$ chuva & 43,3 & 1,0 & 8,4 & 13,7 & 12,4 & 21,1 \\
\hline$+3^{\circ} \mathrm{C}+15 \%$ chuva & 76,3 & 3,6 & 0,0 & 6,2 & 7,7 & 6,1 \\
\hline \multirow[t]{2}{*}{$+5,8^{\circ} \mathrm{C}+15 \%$ chuva } & 97,4 & 0,1 & 0,0 & 1,1 & 0,1 & 1,4 \\
\hline & \multicolumn{6}{|c|}{ Goiás } \\
\hline Atual & 61,6 & 0,0 & 0,0 & 0,0 & 0,0 & 38,4 \\
\hline$+1^{\circ} \mathrm{C}+15 \%$ chuva & 85,9 & 0,0 & 0,0 & 0,0 & 0,0 & 14,1 \\
\hline$+3^{\circ} \mathrm{C}+15 \%$ chuva & 99,9 & 0,0 & 0,0 & 0,0 & 0,0 & 0,1 \\
\hline$+5,8^{\circ} \mathrm{C}+15 \%$ chuva & 100,0 & 0,0 & 0,0 & 0,0 & 0,0 & 0,0 \\
\hline & \multicolumn{6}{|c|}{ Paraná } \\
\hline Atual & 29,6 & 3,0 & 57,2 & 0,0 & 10,1 & 0,0 \\
\hline$+1^{\circ} \mathrm{C}+15 \%$ chuva & 13,2 & 13,1 & 56,3 & 0,0 & 17,4 & 0,0 \\
\hline$+3^{\circ} \mathrm{C}+15 \%$ chuva & 33,3 & 16,4 & 0,0 & 0,0 & 50,3 & 0,0 \\
\hline$+5,8^{\circ} \mathrm{C}+15 \%$ chuva & 74,8 & 19,7 & 0,0 & 0,0 & 5,4 & 0,0 \\
\hline & \multicolumn{6}{|c|}{ São Paulo } \\
\hline Atual & 23,9 & 15,4 & 20,8 & 0,7 & 39,1 & 0,0 \\
\hline$+1^{\circ} \mathrm{C}+15 \%$ chuva & 41,5 & 21,8 & 6,9 & 0,0 & 29,8 & 0,0 \\
\hline$+3^{\circ} \mathrm{C}+15 \%$ chuva & 69,6 & 15,4 & 0,0 & 0,0 & 15,0 & 0,0 \\
\hline$+5,8^{\circ} \mathrm{C}+15 \%$ chuva & 96,6 & 2,2 & 0,0 & 0,0 & 1,1 & 0,0 \\
\hline
\end{tabular}


am Alagoa, Aiuruoca, Baependi, Bocaina de Minas, Bom Jardim de Minas, Brasópolis, Bom Repouso, Bueno Brandão, Camanducaia, Campestre, Carvalhos, Córrego Bom Jesus, Delfim Moreira, Gonçalves, Itapeva, Itamonte, Liberdade, Lima Duarte, Marmelópolis, Ouro Fino, Paraisópolis, Passa Quatro, Piranguçu, Rio Preto, Sapucaia-Mirim, Santa Rita de Jacutinga, Senador Amaral e Wenceslau Braz .

$\mathrm{O}$ aumento de temperatura de $1^{\circ} \mathrm{C}, 3^{\circ} \mathrm{C}$ e $5,8^{\circ} \mathrm{C}$ promoveu uma importante alteração nas regiões aptas para o cultivo do café no Estado de São Paulo. No zoneamento atual, existem cinco níveis de condições climáticas: favorável, favorável com restrição térmica, favorável com irrigação, favorável sujeita a geadas e inapta (Figura 3). Considerando um aumento de $3^{\circ} \mathrm{C}$ na temperatura média anual, surgem três condições: favorável, favorável com restrição térmica e inapto, ampliando a área inapta para 69,6\%. Fica evidente o deslocamento da área produtiva para as regiões de maior altitude, restringindo o cultivo do café na região noroeste do Estado. No cenário mais extremo, com aumento
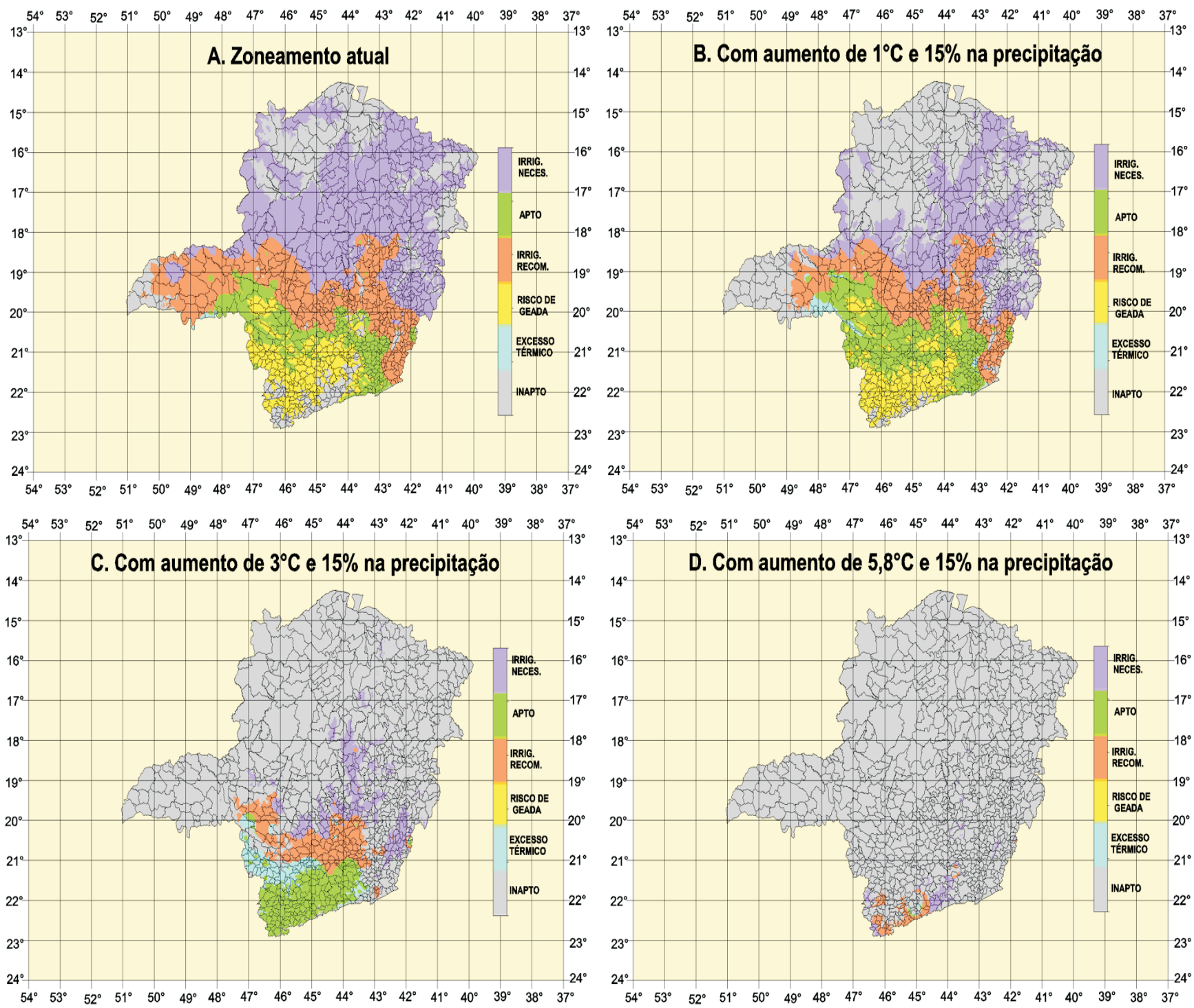

Figura 2. Zoneamento atual do café para o Estado de Minas Gerais (A); Zoneamento considerando aumento de $1^{\circ} \mathrm{C}$ na temperatura e $15 \%$ na precipitação pluvial (B); Zoneamento considerando aumento de $3^{\circ} \mathrm{C}$ na temperatura e $15 \%$ na precipitação pluvial (C); Zoneamento considerando aumento de 5, $8^{\circ} \mathrm{C}$ na temperatura e $15 \%$ na precipitação pluvial (D). 
da temperatura de $5,8^{\circ} \mathrm{C}$, o cultivo do cafeeiro ficará restrito às áreas montanhosas, e a área inapta é ampliada para 96,6\% do Estado. Nessas condições, o cafeeiro poderá ser cultivado nos seguintes municípios: Apiaí, Campos do Jordão, Cunha (parte alta), Divinolândia, Ribeirão Branco, Bananal (parte alta), São José do Barreiro e São Sebastião da Grama.

No Estado do Paraná, com o incremento de $1^{\circ} \mathrm{C}$ na temperatura, ocorre um aumento na área apta com deslocamento da área produtiva para o sul do Estado (Figura 4). Esse deslocamento se acentua no cenário intermediário, ou seja, aumento de $3^{\circ} \mathrm{C}$ na temperatura, já sendo observada redução na área apta de 86,8\% (Cená- rio 1) para $66,7 \%$ do estado. Quando atinge-se $5,8^{\circ} \mathrm{C}$, a redução é de $25,2 \%$ da área. A maior conseqüência é o deslocamento da produção para a região sul do Estado e, possivelmente, com o aumento da precipitação pluvial ocorrerá perda de qualidade do café.

Em todos os casos, o aumento de temperatura acentuará o abortamento de flores, fator restritivo para manutenção da produtividade do cafeeiro.

Esses cenários podem ser contornados considerando-se duas situações. A primeira se forem rapidamente implementadas práticas mitigadoras, que permitam aumentar o seqüestro de carbono, reduzindo o efeito estufa. Entretanto, não é essa situação que está sendo


Figura 3. Zoneamento atual do café para o Estado de São Paulo (A); Zoneamento considerando aumento de $1^{\circ} \mathrm{C}$ na temperatura e 15\% na precipitação pluvial (B); Zoneamento considerando aumento de $3^{\circ} \mathrm{C}$ na temperatura e $15 \%$ na precipitação pluvial (C); Zoneamento considerando aumento de 5,8 ${ }^{\circ} \mathrm{C}$ na temperatura e $15 \%$ na precipitação pluvial (D). 


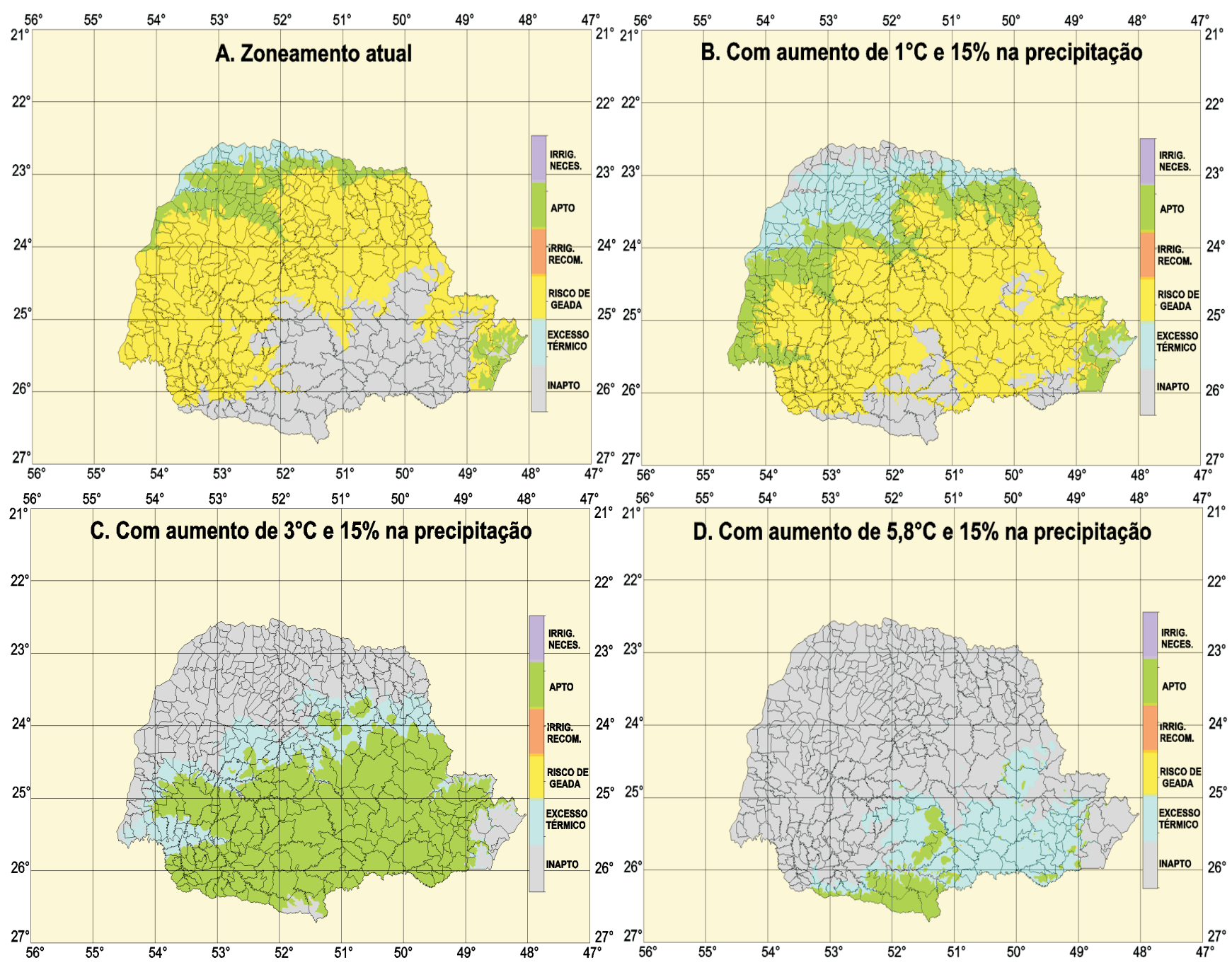

Figura 4. Zoneamento atual do café para o Estado do Paraná (A); Zoneamento considerando aumento de $1^{\circ} \mathrm{C}$ na temperatura e 15\% na precipitação pluvial (B); Zoneamento considerando aumento de $3^{\circ} \mathrm{C}$ na temperatura e $15 \%$ na precipitação pluvial (C); Zoneamento considerando aumento de $5,8^{\circ} \mathrm{C}$ na temperatura e $15 \%$ na precipitação pluvial (D).

verificada. Os trabalhos de Moraes (2004), entre outros, fortalecem a observação de que o aumento de temperatura é evidente. A segunda diz respeito ao melhoramento de plantas para adaptá-las aos estresses ambientais. Assim, para manter a produção de café no Brasil, nos próximos anos, tanto no que diz respeito à qualidade e com a quantidade, deve-se tomar medidas que levem em consideração a possibilidade de a temperatura média do ar sofrer um acréscimo mínimo de $1^{\circ} \mathrm{C}$ a $3^{\circ} \mathrm{C}$.

\section{Conclusões}

1. Comprovados os cenários atuais preconizados pelos modelos do IPCC, considerando um aumento de $1^{\circ} \mathrm{C}$, $3^{\circ} \mathrm{C}$ e $5,8^{\circ} \mathrm{C}$ na temperatura média anual do globo, o cultivo do café arábica nos estados de Goiás, Minas Gerais, São Paulo e Paraná será drasticamente reduzido nos próximos 100 anos, se mantidas as condições genéticas e fisiológicas das atuais variedades.

2. No caso de Goiás, Minas Gerais e São Paulo, a restrição ao cultivo atingirá mais de $95 \%$ da área dos estados, inviabilizando praticamente a cultura do cafeeiro.

3. Nos cenários estudados, o deslocamento da produção será para áreas montanhosas, de difícil manejo, onde temperaturas médias anuais abaixo de $23^{\circ} \mathrm{C}$ ainda serão observadas.

4. No Estado de Minas Gerais, o cultivo se restringirá a 28 municípios (em 2001 foram contabilizados 702 
municípios produtores de café) e, no Estado de São Paulo, o cultivo será restrito a nove municípios (no ano de 2001 foram contabilizados 455 municípios produzindo café); no Estado de Goiás, considerando o aumento de até $3^{\circ} \mathrm{C}$, o cafeeiro será considerado cultura de alto risco, mesmo com a irrigação exercendo a função de suprimento de água e regulador térmico.

5. No Estado do Paraná haverá um deslocamento da área produtiva para a região Sul; mesmo assim, com o aumento de $5,8^{\circ} \mathrm{C}$ na temperatura média anual haverá uma forte redução das áreas aptas para o cafeeiro, saindo de 70,4\% (situação atual) para 25,2\%; com o aumento previsto de chuvas (15\%), a cultura do café no Paraná poderá apresentar problemas de qualidade de bebida, sendo este também um fator restritivo para a cultura.

\section{Referências}

ASSAD, E.D.; EVANGELISTA, B.; SILVA, F.A.M.; CUNHA, S.A.R.; ALVES, E.R., LOPES, T.S.S.; PINTO, H.S.; ZULLO JUNIOR, J. Zoneamento agroclimático para a cultura do café (Coffea arabica L.) no Estado de Goiás e sudoeste do Estado da Bahia. Revista Brasileira de Agrometeorologia, v.9, p.510-518, 2001a. Número especial Zoneamento Agrícola.

ASSAD, E.D.; PINTO, H.S.; CARAMORI, P.H. Zoneamento do Café. Brasília: Consórcio Brasileiro de pesquisas do Café; Embrapa, 2001b. CD-ROM.

BIETO, J.A.; TALON, M. Fisiologia y bioquimica vegetal. Madrid: Interamericana; McGraw-Hill, 1996. p.537-553.

CAMARGO, A.P.C. Clima e a cafeicultura no Brasil. Informe Agropecuário, n.126, p.13-26, 1985.

CAMARGO, M.B.P.; PEDRO JÚNIOR, M.J.; ALFONSI, R.R. Probabilidade de ocorrências de temperaturas absolutas mensais e anual no Estado de São Paulo. Bragantia, v.52, p.161-168, 1993.

CARAMORI, P.H.; CAVIGLIONE, J.H.; WREGE, M.S.; GONÇALVES, S.L.; FARIA, R.T.; ANDROCIOLI FILHO, A.; SERA, T.; CHAVES, J.C.D.; KOGUISHI, M.S. Zoneamento de riscos climáticos para a cultura de café (Coffea arabica L.) no Estado do Paraná. Revista Brasileira de Agrometeorologia, v.9, p.486494, 2001. Número especial Zoneamento Agrícola.

DRINNAN, J.E.; MENZEL, C.M. Temperature affects vegetative growth and flowering of coffee (Coffea arabica L.). Journal of Horticultural Science, v.70, p.25-34, 1995.

ESTADOS UNIDOS. Department of the Interior. Geological Survey. USGS EROS Data Center. Distributed Active Archive Center. 2001.
Disponível em: <http://edcdaac.usgs.gov/gtopo30/ getopo30.asphtml> Acesso em: nov. 2004.

IPCC. Climate change 2001: working group II: Impacts, adaptations and vulnerability. Disponível em: <http://www.grida.no/climate/ipcc_tar/wg2/005.html> Acesso em: nov. 2004

KALNAY, E.; CAI, M. Impact of urbanization and land-use change on climate. Nature, v.423, p.528-531, 2003.

MARENGO, J.A. Impactos das condições climáticas e da variabilidade e mudanças do clima sobre a produção e os preços agrícolas: ondas de frio e seu impacto sobre a cafeicultura nas regiões sul e sudeste do Brasil. In: LIMA, M.A.; CABRAL, O.M.R.; MIGUEZ, J.D.G. (Org.). Mudanças climáticas globais e a agropecuária brasileira. Jaguariúna: Embrapa Meio Ambiente, 2001. cap.4, p.97-123.

MORAES, O.C.C. Ameaça na floresta submersa. Scientific American, n.24, 2004. Disponível em: <www2.uol.com.br/sciam/ conteudo/materia/materia_44html $>$ Acesso em: jun. 2004.

PINTO, H.S.; ALFONSI, R.R. Estimativa das temperaturas médias, máximas e mínimas mensais no Estado do Paraná em função da altitude e latitude. São Paulo: USP, 1974. 30p. (Caderno de Ciências da Terra, 52).

PINTO, H.S.; ORTOLANI, A.A.; ALFONSI, R.R. Estimativa das temperaturas médias mensais do Estado de São Paulo em função da altitude e latitude. São Paulo: USP, 1972. 20p. (Caderno Ciências da Terra, 23).

PINTO, H.S.; ZULLO JUNIOR, J.; ASSAD, E.D.; BRUNINI, O.; ALFONSI, R.R.; CORAL, G. Zoneamento de riscos climáticos para a cafeicultura do Estado de São Paulo. Revista Brasileira de Agrometeorologia, v.9, p.495-500, 2001. Número especial Zoneamento Agrícola.

SALATI, E.; SANTOS, A.A. dos; NOBRE, C. As mudanças climáticas globais e seus efeitos nos ecossistemas brasileiros. Disponível em: <www.comciencia.br/reportagens/clima/ clima14.htm> Acesso em: 25 Jun. 2004.

SEDIYAMA, G.C.; MELO JUNIOR, J.C.; SANTOS, A.R.; RIBEIRO, A.; COSTA, M.H.; HAMAKAWA, P.J.; COSTA, J.M.N.; COSTA, L.C. Zoneamento agroclimático do cafeeiro (Coffea arabica L.) para o Estado de Minas Gerais. Revista Brasileira de Agrometeorologia, v.9, p.501-509, 2001. Número especial Zoneamento Agrícola.

THOMAS, C.D.; CAMERON, A.; GREEN, R.E.; BAKKENES, M.; BEAUMONT, L.J.; COLLINGHAM, C.Y.; ERASMUS, B.F.N.; SIQUEIRA, M.F. de; GRAINGER, A.; HANNAH, L.; HUGHES, L.; HUNTLEY, B.; JAARSVELD, A.S. van; MIDGLEY, G.F.; MILLES, L.; ORTEGA-HUERTA, M.A.; PETERSON, T.A.; PHILLIPS, L.O.; WILLIANS, S.E. Extinction risk from climate change. Nature, v.427, p.145-148, 2004.

THORNTHWAITE, C.W.; MATHER, J.R. The water balance. New Jersey: Centerton, 1955. 104p. (Publications in Climatology, v.8, n.1).

Recebido em 20 de outubro de 2003 e aprovado em 15 de julho de 2004 